\title{
Classification of Sugarcane Genotypes Based on Heat Stress and Morphological Parameters
}

\author{
Syed Rizwan Abbas, Asad Hussain Shah, Aurangzeb Rao \\ Department of Plant Breeding and Molecular Genetics, Faculty of Agriculture \\ University of Azad Jammu and Kashmir, Pakistan \\ E-mail: drsyedrizwanabbas@gmail.com
}

Syed Dilnawaz Ahmad Gardazi

Vic Chancellor of University of Azad Jammu and Kashmir, Muzaffarabad Azad Jammu and Kashmir, Pakistan

Syed Mubashir Sabir

Faculty of Agriculture

University of the Poonch Rawalakot, Azad Jammu and Kashmir, Pakistan

Muhammad Rehan Abbas

Department of Computer Science, University of Azad Jammu and Kashmir, Pakistan

Attiya Batool, RizwanTaj Khan

Department of Botany, University of Azad Jammu and Kashmir, Pakistan

Nisar Ahmed Khan

School of Plant, Environmental \& Soil Sciences, Louisiana State University Agricultural Center, USA

Received: December 16, 2012 Accepted: January 3, 2013

doi:10.5296/jas.v1i2.2875 URL: http://dx.doi.org/10.5296/jas.v1i2.2875 


\section{Abstract}

Leaves of thirteen genotypes of sugarcane were treated in the oven for heat stress. The treated leaves were used for the estimation of phenolic contents and the measurement of lipid peroxidation. Minimum moisture loss is showed by CSSG-668 and maximum moisture loss showed by NSG-45. Maximum phenolic contents were observed in HSF-240 $65.7 \mathrm{mg}$ GAE/100 ml) and minimum results showed by Lho 83-153 and CP-43-33 (32.98 and $33.78 \mathrm{mg}$ GAE/100 ml). Lho 83-153, HSF-242 and S-2002-US-133 were showed high tolerant against heat therefor, showed higher membrane stability, maintenance of high $\mathrm{fv} / \mathrm{fm}$ ratio under heat stress and lower lipid peroxidation of membranes. Hence, the relative tolerance of genotype to heat stress as reflected by its lower lipid peroxidation, higher membrane stability and pigment concentration is related to the levels of activity of its antioxidant enzymes.

Keywords: Sugarcane, Heat stress, Lipid peroxidation, Phenolic contents, Morphological parameters

\section{Introduction}

Sugarcane (Saccharum officinarum L.), an important cash crop of Pakistan, plays a vital role in the economic of farmers and is a survival of the ever-expanding sugar industry in Punjab. Pakistan is a significant cane producing country; it is ranked fifth in the world cane acreage and is 15 th in sugar production. Sugarcane is grown on over a million hectares and delivers the raw materials for Pakistan's 84 sugar mills, which comprise the country's second largest agro-industry after textiles (Rehman, 2009). Thus evolution of new high cane and sugar yielding varieties and improved production technology that is, better management practices (BMPs) are current need for improving livelihoods of sugarcane growers and other crops and ultimately betterment of mill owners also (Nasir, 2006; Iftikhar et al., 2010). Addition of organic matter in soil improves the physicochemical and biological properties. Assessment of adaptation, performance of various cane varieties in different ecologies, and evaluation of agronomic characters of exotic cane varieties are necessary before a variety is introduced for commercial cultivation. Cane yield and cane sugar evaluation of varieties were generally done on stalk, stalk height, stalk girth, stalk weight and fiber contents (Akhtar et al., 2000). The major commercial sugar estates in Pakistan are all located in its Punjab and Sindh region: an ecological zone that is often subject to varying periods of drought due to inadequate and erratic distribution of rainfall. This poses a serious problem for sugar-cane, which has a 10 to 12 -month crop cycle. When drought occurs during the formative growth phase (0 to 120 days after planting), the crop experiences slow growth, which subsequently results in low cane yield (Barnes, 1974). In order to improve sugar yields, it is necessary to develop cultivars that remain productive under low soil moisture availability. Screening for drought tolerance can be achieved by simulating moisture stress at the critical growth stage of the crop, either under controlled atmosphere conditions or under field conditions.

Little success has been achieved in screening plants for drought tolerance by selection for morphological features due to genotype $\times$ environment interactions (Bendelow et al., 1955). Blum (1988) hypothesized that the simplest approach for drought tolerance would be to utilize the natural stress of the field environment to screen genotypes. Despite the relatively drought 
tolerant nature of the sugar-cane plant, varieties differ markedly in their tolerance to drought (Moore, 1987). Sugar-cane varieties susceptible to drought are likely to have wilt, early reduction of cane production; while tolerant varieties remain turgid and maintain near-optimum growth for longer production (Moore, 1987). Tolerant varieties have the ability to reduce transpiration losses, maintaining at the same time adequate absorption of water from the soil.

The mechanism of the toxic effect of organophosphate compounds involves the inhibition of acetylcholinesterase and other non-specific esterases through phosphorylation at - $\mathrm{OH}$ serine in the esterase centre of the enzyme. This mechanism is the same for all insecticides of the group, irrespective of differences in their chemical structure (Lotti, 2001). The inhibition of the activity of cholinesterase enzymes causes an increase in the level of endogenous acetylcholine in the organism and results in its binding to muscarinic and nicotinic receptors in both the peripheral and central nervous systems. This increase in the central nervous system $(C N S)$ disturbs the balance between neurotransmitters and causes the onset of acute intoxication symptoms (Lotti, 2001). The symptoms of acute intoxication with organophosphates have been well described, while the effects of chronic exposure to these compounds are not completely clear. Many authors postulate that they may have an effect on redox processes in a number of organs, thus, leading to disturbances in these processes and causing enhancement of lipid peroxidation, both in acute and chronic intoxication by these compounds (Abdollahi, 2004; Sharma, 2005). As increased generation of reactive oxygen species and lipid peroxidation induced by these species underlies many diseases, it is extremely important to determine the effect of organophosphate insecticides on lipid peroxidation processes (Mates, 1999; Yagi, 1987).

The objective of this study was to look for drought tolerance sugar-cane germplasm in Pakistan. Such screening will aid in the classification of genotypes, in the selection of commercial sugar-cane cultivars, and in the identification of parents to genetically improved drought tolerance in sugar cane cultivars developed for Pakistan.

\section{Materials and Methods}

Sugarcane genotypes were collected from sugarcane growing agencies of Pakistan and cultivated in the Glasshouse of Faculty of Agriculture, Rawalakot.

\subsection{Morphological Parameters}

Thirteen local sugarcane accessions or varieties namely HSF-240, SPF-213, CP-77-400, HSF-242， CP-43-33， NSG-45， NSG-60， CPF-198， CSSG-668， S-2002-US-133, S-2003-US-718, Lho 83-153 and NSG- 555 planted in the Glasshouse of Faculty of Agriculture, Rawalakot were used for this study. The experiment was laid out in a randomized complete block design (RCBD) with three replications. All agronomic practices were kept normal for all the 13 genotypes. Data on plant height $(\mathrm{cm})$, number of tillers per plant, number of leaves, cane diameter $(\mathrm{cm})$, leaf area $\left(\mathrm{cm}^{2}\right)$, intermodal distance $(\mathrm{cm})$, number of nodes were collected from 10 randomly selected stalks from each replication. 


\subsection{Heat Stress in the Laboratory}

Three leaves were selected randomly from 13 sugar-cane accessions for laboratory screening. The leaves were cut early in the morning from mature cane stalks between the 5th and 6th leaf from top visible dewlap. Leaf area was calculated based on 3/4 of length and breadth of the product (Barnes 1974). The leaves were weighed and kept in an oven at $35^{\circ} \mathrm{C}$ for three hours. Percentage $(\%)$ of moisture loss from the excised leaves was determined using the formula of Blum (1988): $\{($ Fresh weight -Dry weight $) /($ Dry weight $) \times 100\}$.

\subsection{Phenolic Contents}

The total phenol content was determined by adding $0.5 \mathrm{ml}$ of the aqueous extract to $2.5 \mathrm{ml}$, $10 \%$ Folin-Ciocalteau's reagent $(\mathrm{v} / \mathrm{v})$ and $2.0 \mathrm{ml}$ of $7.5 \%$ sodium carbonate. The reaction mixture was incubated at $45^{\circ} \mathrm{C}$ for $40 \mathrm{~min}$, and the absorbance was measured spectrophotometrically at $765 \mathrm{~nm}$. Gallic acid was used as a standard phenol (Singleton et al., 1999). The mean of three readings was used and the total phenol content was expressed as milligram of gallic acid equivalents/ $\mathrm{g}$ extract.

\subsection{Lipid Peroxidation Estimation}

The level of malonyldialdehyde, as a substance that reacts with thiobarbituric acid (TBARS), was determined in the homogenates of the organs and in the serum according to the method of Buege et al. (1978). 10\% homogenates of tissues were added to $0.15 \mathrm{~m} \mathrm{KCl}$ and centrifuged at $10000 \mathrm{x} \mathrm{g}$ for $30 \mathrm{~min}$. To $0.5 \mathrm{ml}$ of supernatant or $0.5 \mathrm{ml}$ of serum, $0.5 \mathrm{ml}$ of $50 \%$, trichloroacetic acid was added and centrifuged again at $5000 \mathrm{x} \mathrm{g}$ for $5 \mathrm{~min}$. After the final centrifugation, the tubes with $0.5 \mathrm{ml}$ of supernatant and $0.5 \mathrm{ml}$ of thiobarbituric acid covered with aluminium foil were kept in a water bath at $90^{\circ} \mathrm{C}$ for $1 \mathrm{~h}$. The absorbance was read at 540 $\mathrm{nm}$ at room temperature against the blank and then concentration of thiobarbituric acid reactive substances was read from standard calibration curve, which was plotted using 1, 1, 3, 3'tetraethoxy propane. The resulting concentration of TBARS was presented in micromoles of TBARS per $\mathrm{dm}^{3}$ of serum or in nanomoles of TBARS on $\mathrm{g}$ of tissue.

\section{Results and Discussion}

\subsection{Morphological Parameters}

Three logical clusters I, II and III were based on morphological parameters. In cluster I, HSF-240, NSG-60 and CP-77-400 were present. In cluster II SPF-213, CP-43-33, NSG-45 and NSG-555 were present and HSF-242, CPF-198, CSSG-668, S-2002-US-133, Lho 83-153 and S-2003-US-718 were present in cluster III. HSF-240 and S-2003-US-718 showed maximum difference because total height of plant, leaves length, number of internodes and number of tillers vary from each other. Clusters II and I were connected on gene linkage 77 due to cane diameter and leaf size similarities; they had dissimilarities in plant height, number of tillers, internode distance and number of internodes as shown in Figure 5. Clusters I and II differ from cluster III due to plant height, internode distance, cane diameter and number of leaves; but their similarities are due to leaf size. Therefore, clusters I and II are connected to cluster III on 138 gene linkage as shown in Figure 1. 


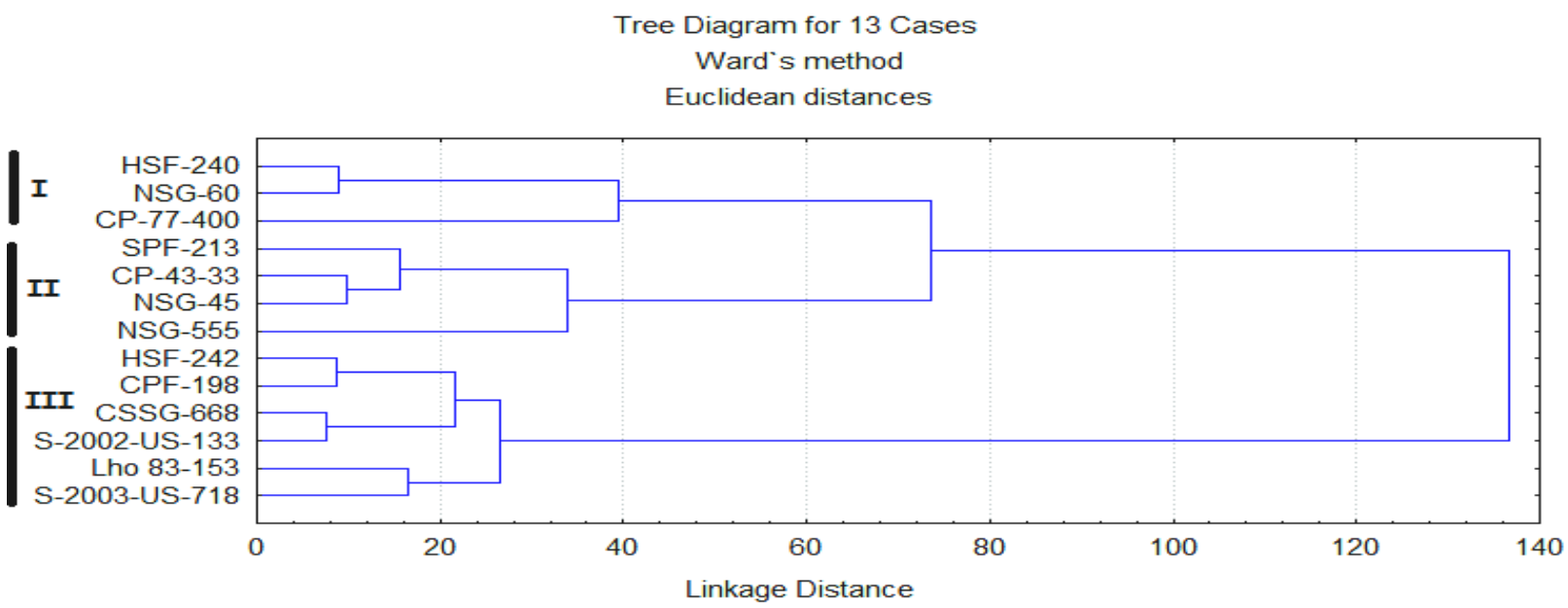

Figure 1. Dendrogramme of morphological data of thirteen sugarcane genotypes.

\subsection{Total Moisture Loss}

Mean percent moisture loss from excised leaves, which is an index of moisture stress, is presented in Figure 2. Minimum moisture loss is found in HSF-240 and CSSG-668 (74.99 and $74.64 \%$ respectively) and maximum moisture loss in CP-43-33 and NSG-45 (84.033 and $83.948 \%$ respectively); they were observed to lose more moisture than accessions with smaller leaf area, as a result of their larger evaporating surface for transpiration. Although leaves of some accessions with large surface area lost much moisture when subjected to oven temperature, some accessions with small leaf area also exhibited similar behaviour. Barnes (1974) attributed such response to the presence of many stomata and large bulliform cells in the leaves, whereas Meneses (1986) attributed it to the release of electrolytes from the cells. Varieties that are least damaged by heat (that is, low moisture loss) are likely to be tolerant to drought. This had been observed also in the study of Viqueira et al., (1984).
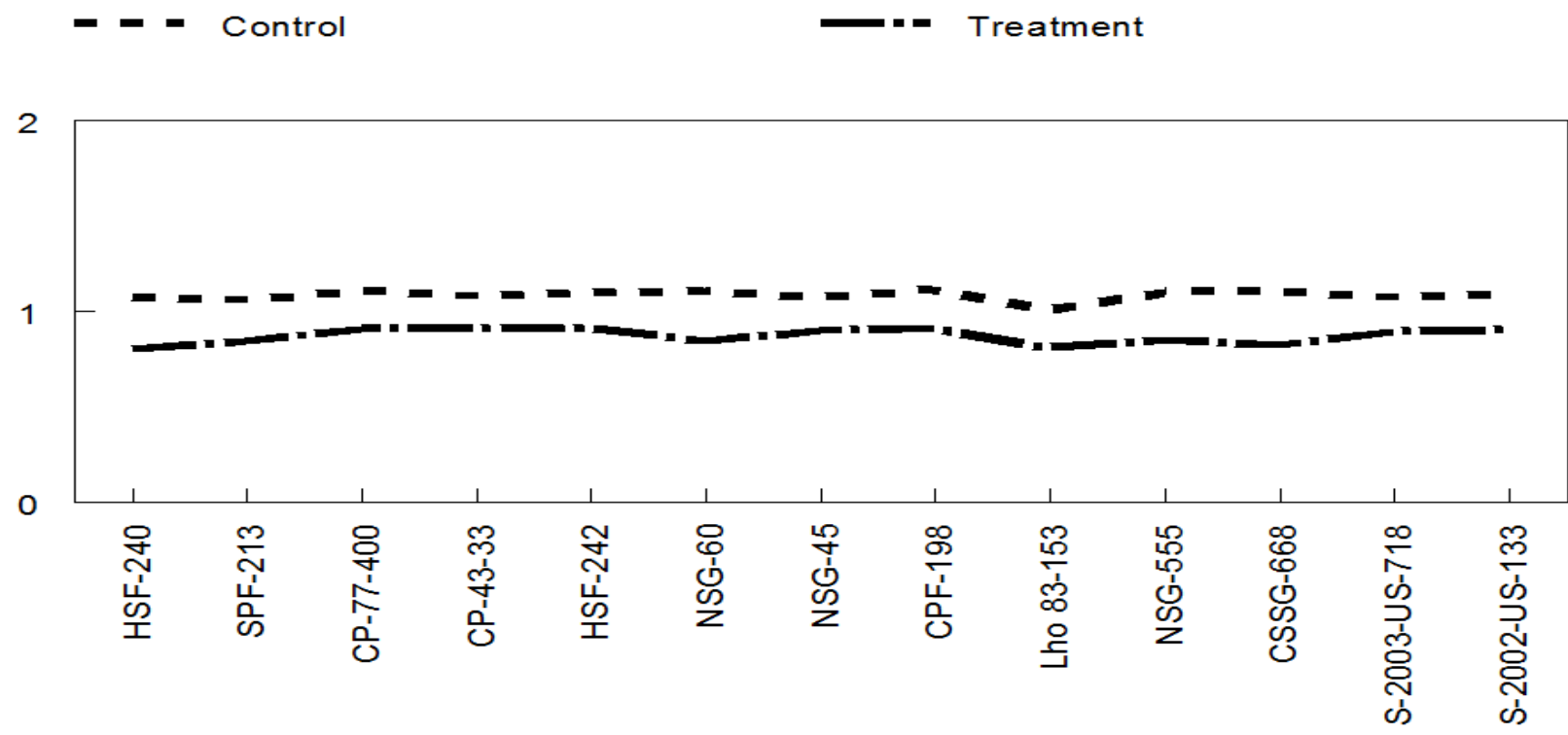

Figure 2. Result of thirteen genotypes of sugarcane (heat treatment).

\subsection{Total Phenolic Compounds}


The total phenolic contents in extracts obtained from the control and heat treated leaves of sugarcane are shown in Figure 3. HSF-240 showed high results $(65.7 \mathrm{mg} \mathrm{GAE} / 100 \mathrm{~mL})$ at control and after treatment the absorbance decreased (49.56 mg GAE/100 mL). CPF-198 and NSG-45 showed the best results of 53.73 and $51.87 \mathrm{mg} \mathrm{GAE} / 100 \mathrm{~mL}$ at control and gradually decreased when stress increased. After treatment these genotypes showed results of 37.88 and $34.65 \mathrm{mg}$ GAE/100 mL. Lho 83-153 and CP-43-33 showed lowest values of 32.98 and 33.78 $\mathrm{mg} \mathrm{GAE} / 100 \mathrm{~mL}$ ) at control and after treatment the values were 19.41 and $21.76 \mathrm{mg} \mathrm{GAE} / 100$ $\mathrm{mL}$, as seen in Figure 3. Triantaphyllou et al., (2001) stated that the extracts of Mentha species contained bound phenolic acids and flavonoids. The major phenolic acids reported in water-soluble Mentha spicata extract are eriocitrin, luteolin glucoside, rosmarinic acid and caffeic acid (Dorman et al., 2003). Phenolic compounds present in these extracts are reported to have beneficial effects on other chronic diseases such as coronary heart disease (Forester and Waterhouse, 2009). These health effects are reported to be due to antiradical and antioxidant properties of phenolics in plants and their derivatives (Lurton, 2003).

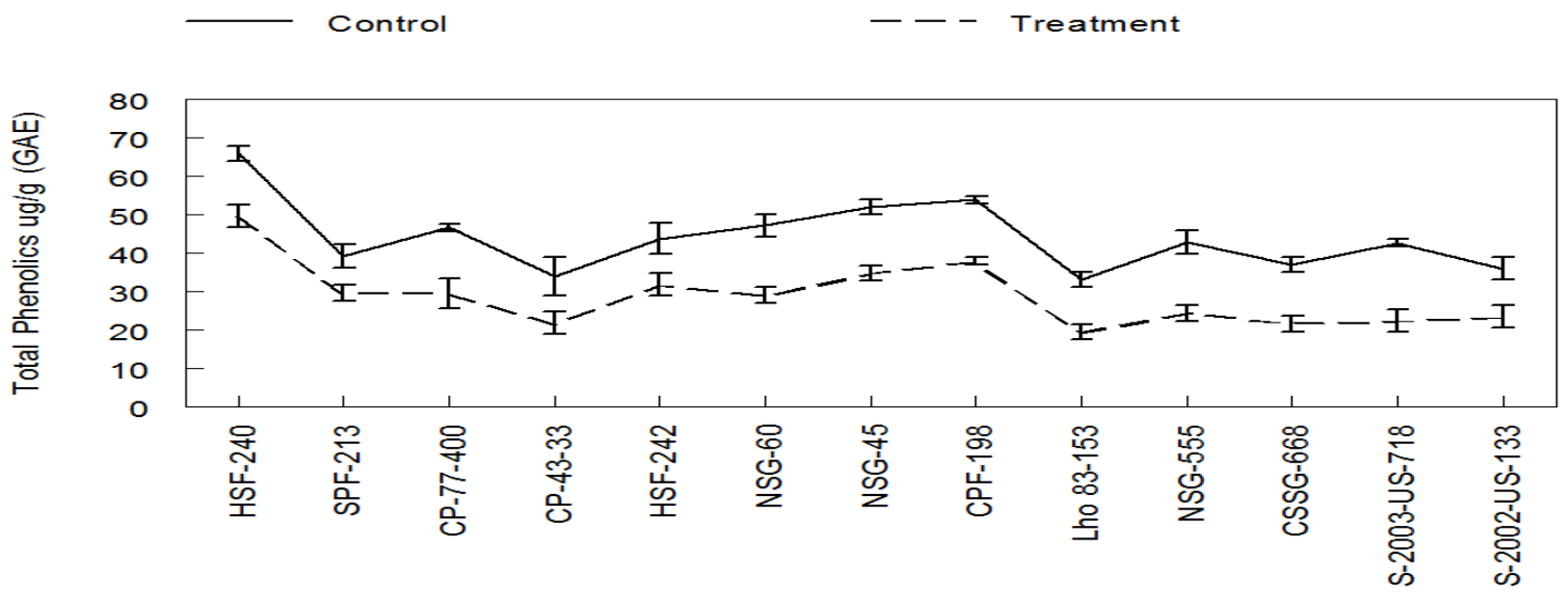

Figure 3. Thirteen genotypes of sugarcane (total phenolics).

\subsection{Estimation of Lipid Peroxidation}

Lipid peroxidation (LPO) as MDA content, estimated at formative and grand growth phase of the crop, showed increasing trend over the stage as well as heat stress condition (Figure 2). Under control, Lho 83-153, HSF-242 and S-2002-US-133 showed minimum values of 26.815, 32.395 and 34.125 (nmol malondialdehyde g- ${ }^{1}$ f.wt) respectively, and after heat treatment the values increased due to stress and showed value of 37.045, 38.905 and $43.555 \mathrm{nmol}$ malondialdehyde g- ${ }^{1}$ f.wt, respectively. CP-77-400, HSF-240 and NSG-60 showed maximum values of 47.43, 45.57 and $41.075 \mathrm{nmol}$ malondialdehyde $\mathrm{g}-{ }^{1}$ f.wt. respectively; after treatment the values increased and moved to 56.42, 56.575 and $49.9125 \mathrm{nmol}$ malondialdehyde $\mathrm{g}-{ }^{1} \mathrm{f}$.wt as seen in Figure 4. The stress induced increase in leaf membrane damage, reduced uptake of $\mathrm{CO}_{2}$ because of closer stomatal, decreased hydrolytic enzyme activity and increased lipid peroxidation level; it may stimulate formation of AOS such as superoxide, hydrogen peroxide, and hydroxyl radicals. Among AOS, superoxide converted by SOD enzyme into $\mathrm{H}_{2} \mathrm{O}_{2}$, is further scavenged by CAT and various peroxidases. APOX and GR also play a key role by reducing $\mathrm{H}_{2} \mathrm{O}_{2}$ to water through the Halliwell-Asada pathway (Noctor and Foyer, 1998). Allen 


\section{Macrothink}

(1995) also reported that much injury of plants caused by various stresses is associated with oxidative damage at cellular level such as cell membrane damage.

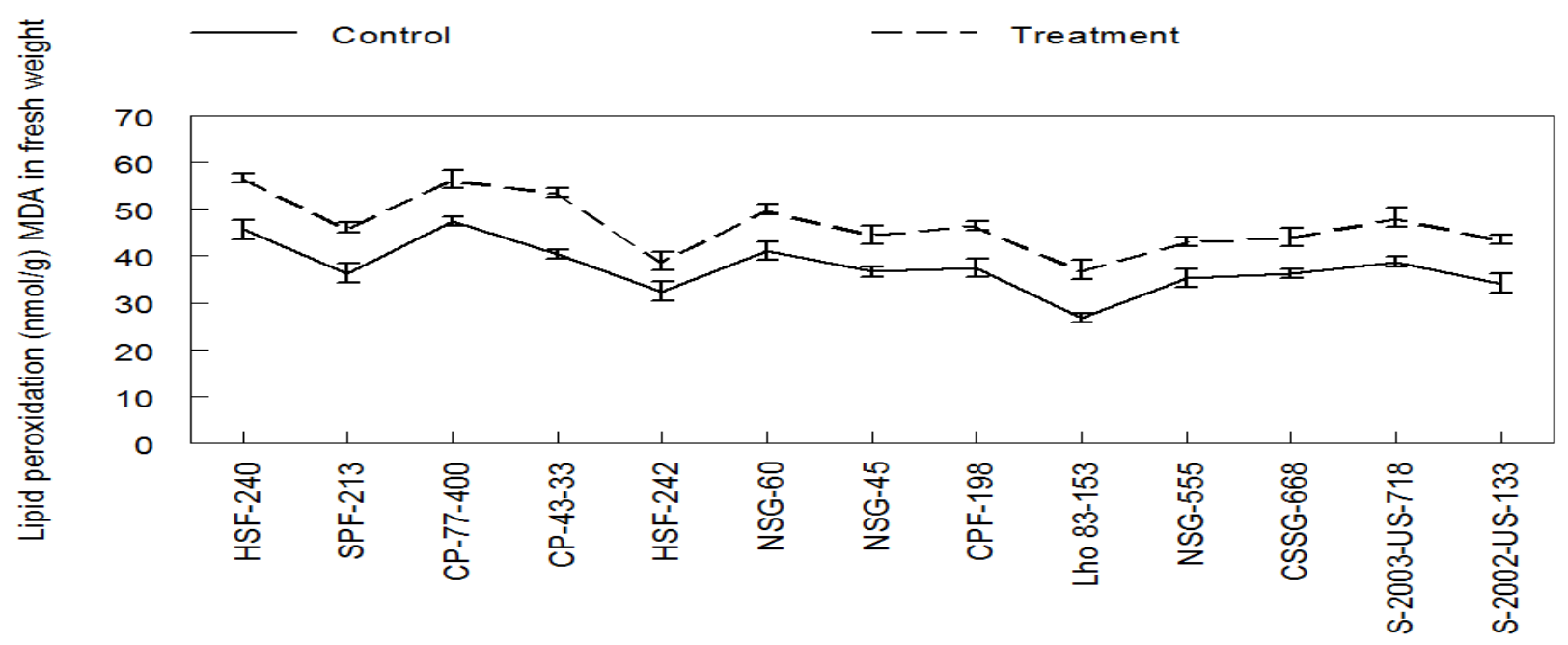

Figure 4. Thirteen genotypes of sugarcane (lipid peroxidation).

Cluster analyses can be used for the screening of thirteen genotypes of sugarcane by using MDA, phenolic and moisture loss through heat stress experiment. Cluster I having HSF-240, CPF-198 and CSSG-668, and cluster II having CP-77-400, NSG-60, NSG-45, NSG-555 and S-2003-US-718 were present. Cluster III has SPF213, HSF-242, CP-43-33, Lho 83-153 and S-2002-US-133. As a result, cluster III is more heat tolerant than cluster I. S-2002-US-133 and Lho 83-153 are more heat tolerant than HSF-240 in Figure 5.

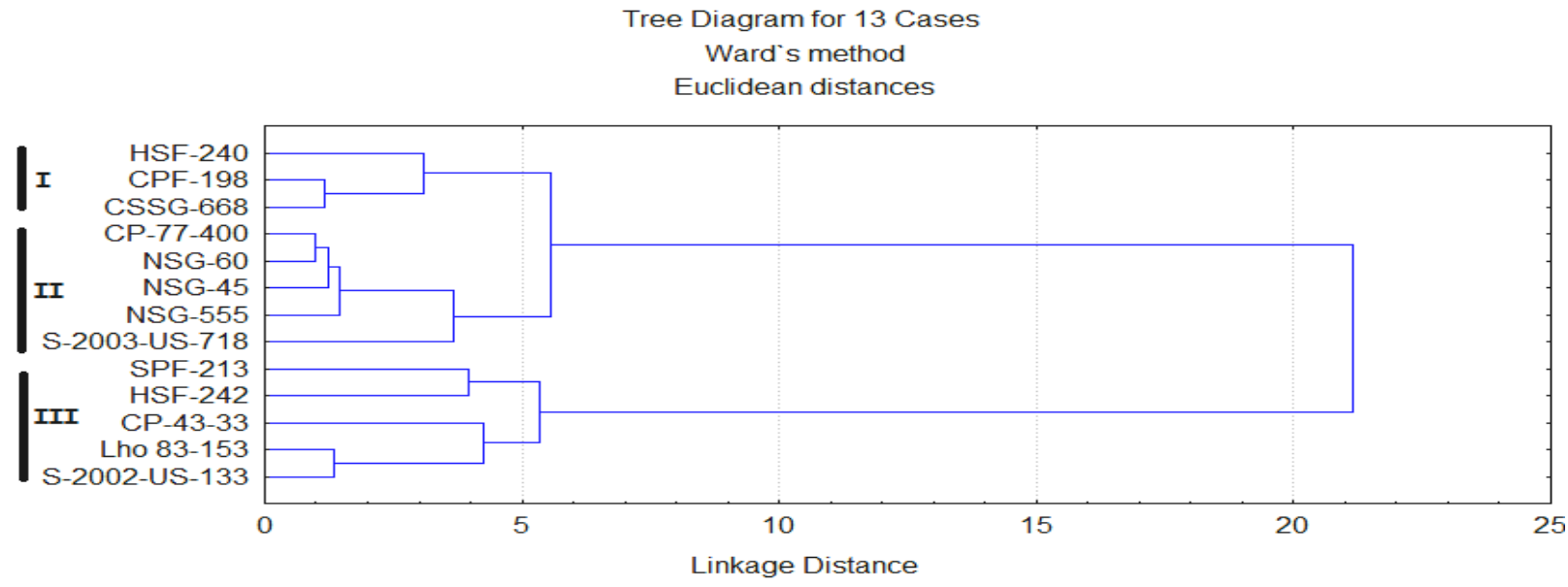

Figure 5. Dendrogramme of heat stress.

\section{References}

Akhtar. M. Bashir. K. Akhtar. M. E. Khan. M. Z., \& Rafiq. Ch. (2000). Effect of timing of nitrogen application on agronomic characters and nutrient contents of sugarcane (Sacharum officinarum L). Pakistan J. Biol. Sci. 3, 672-673.

Allen RD (1995). Dissection of oxidative stress tolerance using transgenic plants. Plant 
Physiol., 107, 1049-1054.

Abdollahi M., Mostfalou S., Poournoourmoohamadi S., \& Shadnia S. (2004) oxidative stress and cholinesterase inhibition in saliva and plasma of rats following subchronic exposure to malathion. comp. bioch. Physiol. 137, 29.

Barnes AC. (1974). The Sugarcane. 2nd ed. Hill Books, London, UK. 572.

Bendelow VW, Meredith WOS. (1955). Reliability of prediction tests for malting quality of barley. Canadian Journal of Agricultural Science, 35, 252-258.

Blum A. (1988). Plant Breeding for Stress Environments. CRC Press Inc., Florida, USA. 43-77.

Bue. Ge. JA., \& Aust. S. (1978). microsomal lipid peroxidation. methods of enzymology. 51, 302.

Dorman, H. J. D., M. Kosar, K. Kahlos, Y. Holm, \& R. Hiltunen. (2003). Antioxidant properties and composition of aqueous extracts from Mentha species, hybrids, varieties, and cultivars. J. Agric. Food Chem., 51, 4563-4569. http://dx.doi.org/10.1021/jf034108k

Forester, S. C., \& A. L. Waterhouse. (2009). Metabolites are key to understanding health effects of wine polyphenolics. J. Nutr., 138, 1824S-1831S. http://dx.doi.org/10.3945/jn.109.107664

Iftikhar, T., L. K. Babar, S. Zahoor, \& N. G. Khan. (2010). "Best Irrigation Management Practices In Cotton”. Pakistan Journal of Botany, 42(5), 3023-3028.

Lotti M. (2001) clinical toxicology of anticholinesterase agents in humans. Handbook of Pesticide Toxicology, Academic Press, USA, Ed. II, 2, 1043.

Lurton, L. (2003). Grape polyphenols: New powerful health ingredients. Innov. Food Technol., $18,28-30$.

Meneses RS. (1986). Assessment of drought resistance in sugarcane varieties through the determination of the release of electrolytes. Plant Breeding Abstracts 56(11), 1057.

Moore PH. (1987). Physiological basis for varietal improvement in sugarcane. In: Proceedings of the International Symposium on Sugarcane Varietal Improvement. Sugarcane Breeding Institute, Coimbatore, India, 3-7 September 1987. 19-56.

Mates JM., Perez-Gomez C., \& De Catro IN. (1999). Antioxidant enzymes and human diseases. clin. biochem. 32, 595.

Nasir, N. M. (2006). Better management practices for cotton and sugar cane. WWF-Pakistan, Ferozepur Road, Lahore - 54600, Pakistan, pp. 117.

Noctor G, Foyer CH. (1998). Ascorbate and glutathione: keeping active oxygen under control. Annu. Rev. Plant Physiol. Plant Mol. Bio., 49, 249-279. http://dx.doi.org/10.1146/annurev.arplant.49.1.249 


\section{Macrothink}

Journal of Agricultural Studies

ISSN 2166-0379 2013, Vol. 1, No. 2

Rehman, M. S. (2009). Pakistan Sugar Annual 2009.USDA Foreign Agrcultural Service, pp. 3.

Sharma Y., Bashir S., Irshad M.,Gupta SD., \& Dogra TD. (2005). Effects of acute dimethoate administration on antioxidant status of liver and brain of experimental rats. Toxicology, 5, 49. http://dx.doi.org/10.1016/j.tox.2004.06.062

Triantaphyllou, K., G. Blekas, \& Boskou. (2001). Antioxidative properties of water extracts obtained from herbs of thespecies Lamiaceae. Int. J. Food Sci. Nutr., 52, 313-317. http://dx.doi.org/10.1080/09637480120057512

Viqueira L, Gomez L, \& Rodriguez CR. (1984). Tolerance of high temperature in sugarcane. II Estimation of the drought tolerance of different varieties. Plant Breeding Abstracts 54, 335.

Yagi K. (1987). lipid peroxides in human disease. chem. Phys.lipids. 45, 337.

\section{Copyright Disclaimer}

Copyright reserved by the author(s).

This article is an open-access article distributed under the terms and conditions of the Creative Commons Attribution license (http://creativecommons.org/licenses/by/3.0/). 